\title{
Links between Pollen, Atopy and the Asthma Epidemic
}

\author{
Philip E. Taylor ${ }^{a, c}$ Kraig W. Jacobson ${ }^{b}$ James M. House ${ }^{c}$ M. Michael Glovsky ${ }^{c} d$ \\ a School of Botany, University of Melbourne, Parkville, Australia; ${ }^{b}$ Allergy and Asthma Associates, Eugene, Oreg., \\ 'Division of Chemistry and Chemical Engineering, California Institute of Technology, and ${ }^{\mathrm{d}}$ Asthma and Allergy \\ Center, Huntington Medical Research Institute, Pasadena, Calif., USA
}

\section{Key Words}

Air pollution $\cdot$ Asthma $\cdot$ Atopy $\cdot$ Pollen allergens .

Pollen fragments

\begin{abstract}
Pollen allergy has been found in $80-90 \%$ of childhood asthmatics and $40-50 \%$ of adult-onset asthmatics. Despite the high prevalence of atopy in asthmatics, a causal relationship between the allergic response and asthma has not been clearly established. Pollen grains are too large to penetrate the small airways where asthma occurs. Yet pollen cytoplasmic fragments are respirable and are likely correlated with the asthmatic response in allergic asthmatics. In this review, we outline the mechanism of pollen fragmentation and possible pathophysiology of pollen fragment-induced asthma. Pollen grains rupture within the male flowers and emit cytoplasmic debris when winds or other disturbances disperse the pollen. Peak levels of grass and birch pollen allergens in the atmosphere correlated with the occurrence of moist weather conditions during the flowering period. Thunderstorm asthma epidemics may be triggered by grass pollen rupture in the atmosphere and the entrainment of respirable-sized particles in the outflows of air masses at ground level. Pollen contains nicotinamide adenine dinucleotide phosphate (reduced) oxidases and bioactive lipid mediators which likely contribute to the inflammatory response. Several studies have examined synergistic effects and enhanced immune response from interaction in the atmosphere, or
\end{abstract}

from co-deposition in the airways, of pollen allergens, endogenous pro-inflammatory agents, and the particulate and gaseous fraction of combustion products. Pollen and fungal fragments also contain compounds that can suppress reactive oxidants and quench free radicals. It is important to know more about how these substances interact to potentially enhance, or even ameliorate, allergic asthma.

Copyright $\odot 2007$ S. Karger AG, Basel

\section{Introduction}

The prevalence of asthma has increased so rapidly over the past several decades as a result of ill-defined changes in living conditions [1] that it is now described as an epidemic [2]. Although asthma is a multi-factorial airways disease that arises from a genetic background inter-phased with exposures to allergens and irritants, this rise in asthma prevalence is most likely caused by changes in the environment, since it is unlikely that the genetic background of the population has recently changed [3]. A number of environmental factors can affect the development and severity of allergy and asthma, such as exposure to a mix of allergens and airborne irritants (cigarette smoke and traffic emissions), viruses, and endotoxins that are released from bacteria. Early life exposures and infections are believed to play a role (the 'hygiene hypothesis') in the development and severity of asthma. Biological substances, such as pollen and fungi, have a major

\section{KARGER \\ Fax +41613061234 \\ E-Mail karger@karger.ch}

๑) 2007 S. Karger AG, Basel

www.karger.com
Accessible online at: www.karger.com/iaa
Correspondence to: Dr. Philip E. Taylor

School of Botany

University of Melbourne

Parkville, 3010, Vic. (Australia)

Tel./Fax+61393801697, E-Mail taylor@caltech.edu 
Fig. 1. Illustration of a ryegrass flower showing dispersal of the pollen fragments. Low RH triggers unfurling of the anther. High RH causes the anther to reflex, entrapping the pollen grains. Pollen grains rupture within the moistened anther. Upon drying, wind disturbances release fragments of pollen cytoplasmic debris into the air.

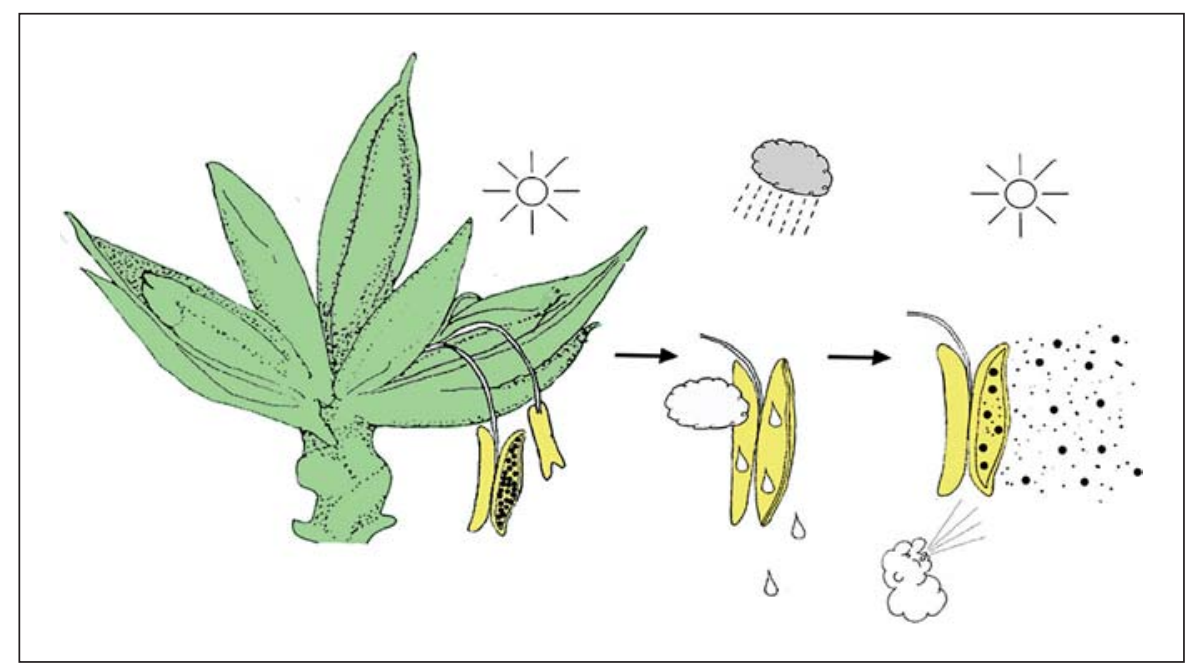

impact, since sensitization to these environmental allergens is an important risk factor for the development of asthma [4].

Climate change is apparently increasing the abundance of aeroallergens such as pollen, which may result in greater incidence or severity of allergic disease [5]. The incidence of allergic disease in Australia is one of the highest in the world [2]. Asthma prevalence almost doubled between the mid-1980s and the mid-1990s, but fell again over the next 10 years. This fall in asthma incidence coincided with a decline in seasonal atmospheric pollen and fungal counts. The reduction in atmospheric bioaerosols was caused by the environmental stress of belowaverage rainfall experienced since the mid-1990s across the more populated regions of south-eastern Australia.

Whole pollen grains are too large to penetrate the small airways [6]. However, episodes of wet weather during the pollen season can trigger pollen grains to emit respirable particles that can penetrate into the lower airways where they may trigger asthmatic responses [7-10]. A mechanism has been demonstrated that involves rupture of pollen grains within their flowers and subsequent release of the discharged cytoplasmic debris when winds or other disturbances disperse the pollen.

\section{Pollen Presentation and Fragmentation}

Wind tunnel experiments, along with video microscopy and time-lapse digital recording, have enabled observation of flowering processes, such as unfurling of the anthers and pollen release, and the influence of moisture.
Two modes of pollen emission are described for allergenic wind-pollinated plants. After unfurling of the anthers, the pollen grains of most wind-pollinating trees, weeds and grasses remain on the anthers and exposed to the atmosphere until disturbed by an external force, for example by wind gusts $[7,10]$. High relative humidity $(\mathrm{RH})$ stimulates the anthers to reflex and partially re-envelope the pollen which are susceptible to rupture (fig. 1). Another mechanism observed in allergenic plants involved the rapid straightening of the stamen and propulsion of pollen grains into the air at speeds in excess of Mach 0.7 [11]. This was observed in mulberry, and the mechanism is common to wall pellitory (Parietaria species) and related taxa. This mode of pollen emission was triggered by a drop in $\mathrm{RH}$, and this underlies the peaks observed in outdoor pollen counts for these species in the early morning or the first spell of dry weather.

The anther has been shown as the site for pollen rupture and the emission of not only pollen grains, but also pollen fragments [7, 10]. Microscopic examination of fresh pollen immersed into water showed that the rate of pollen rupture varied according to the species (table 1; fig. 2; online suppl. video 1, www.karger.com/doi/ 10.1159/000103230). Further experiments were performed with harvested flowers, artificial anthers made of pollen-coated substrates and a diversity of inorganic surfaces. Flowers were housed within a wind tunnel and emissions were detected with an aerodynamic particle sizer. After anthers unfurled under quiescent conditions, $80-95 \%$ of the pollen remained on the anther wall. A minimum threshold wind speed of $2.5 \mathrm{~m} / \mathrm{s}$ was required for both pollen and pollen fragment entrainment. Orbi- 


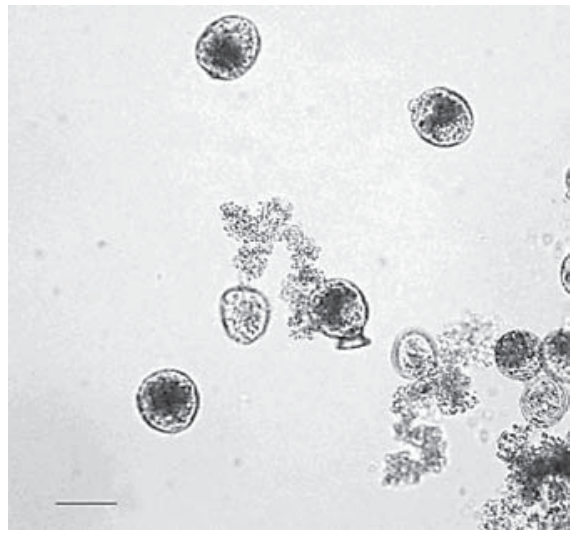

Fig. 2. Ryegrass pollen grain ruptured in water showing release of micrometric particles of fragmented cytoplasmic debris. Still frame taken from online supplement video 1 (www.karger.com/ doi/10.1159/000103230). Scale bar $=30 \mu \mathrm{m}$.

Table 1. Variations in the onset and amount of rupture for a range of allergenic pollen

\begin{tabular}{llc}
\hline Pollen type & $\begin{array}{l}\text { Amount of pollen } \\
\text { ruptured, } \%\end{array}$ & $\begin{array}{l}\text { Time from immer- } \\
\text { sion till rupture }\end{array}$ \\
\hline Grasses & & \\
Ryegrass & 72 & $5 \mathrm{~min}$ \\
Bermuda grass & 65 & $20 \mathrm{~min}$ \\
Orchard grass & 62 & $3 \mathrm{~h}$ \\
Wild oats & $<1$ & $24 \mathrm{~h}$ \\
Trees & & \\
Cypress & 90 & $10 \mathrm{~min}$ \\
Japanese cedar & 60 & $15 \mathrm{~min}$ \\
Walnut & 20 & $25 \mathrm{~min}$ \\
Chinese elm & 65 & $35 \mathrm{~min}$ \\
Orchard grass & 62 & $3 \mathrm{~h}$ \\
Birch & 65 & $5 \mathrm{~h}$ \\
Oak & 50 & $5 \mathrm{~h}$ \\
Olive & 50 & $5 \mathrm{~h}$ \\
Pine & 60 & $3 \mathrm{days}$ \\
Weeds & & $3 \mathrm{~h}$ \\
Plantain & 50 & \\
\hline
\end{tabular}

Freshly collected pollen was stored at approximately $65 \% \mathrm{RH}$ for $1 \mathrm{~h}$ prior to immersion in water (modified from [8]).

cules and other micrometer-sized particles, such as occasional wax and gland fragments from surface abrasion, can be emitted from plants. Orbicules are particles that line the anther and are released from some plants, such as cypress, but few are released from ryegrass [7], and they also play little role in birch allergen distribution [10, 12].

Other features of flower morphology can assist in the distribution of pollen. Grass anthers are generally suspended on a thin elongated filament. Light winds flex this filament. However, at wind speeds in excess of $3 \mathrm{~m} / \mathrm{s}$, Bermuda grass (Cynodon species) anthers rotate in a rapid centripetal motion, and this induces a peak in pollen emission. The emission of pollen from other biological and inorganic substrates required far higher wind speeds. The chemical composition and nanostructure patterning of the pollen wall and anther lining likely reduce the Van der Waals forces of attraction. This results in a lowering of the wind velocity threshold needed to emit pollen grains and pollen debris into the air. The rotating motion of the Bermuda grass anther also aids in the dispersal of pollen grains away from the plant at relatively low wind speeds.

\section{Pollen Fragment Composition}

\section{Allergens}

The majority of studies into allergy symptoms have focused primarily on individual allergens. A range of pollen-specific allergenic proteins has been isolated and identified (http://www.allergome.org) [13]. An adaptive immune response to pollen allergens leads to the recruitment of granulocytes - such as lymphocytes, eosinophils and mast cells - and their inflammatory products in the airways. However, pollen allergens occur in the atmosphere associated with particles of pollen cytoplasm. The airways response to the deposition of pollen fragments has been recently investigated, and new insights into these interactions are beginning to emerge. Pollen fragments contain allergens and a range of other compounds that may be involved in the immune response $[7,9,10,14$, 15]. Fragments of timothy grass pollen induced specific antibodies and lymph node cell responses in the Brown Norway rat [16]. Shin et al. [17] observed mast cell phagocytosis of IgE-bound particulate allergens, followed by the release of intact and immuno-reactive allergens upon IgE-triggered mast cell rupture. They suggested that these expelled allergens may then further contribute to the immune response.

\section{Bioactive Lipid Mediators}

Many fatty acids (linoleic acid, linolenic acid and their fatty acid octadecanol metabolites) have been identified in aqueous extracts from birch and grass pollen. Experi- 
ments in vitro showed that these fatty acids activated and recruited polymorphonuclear leucocytes [15]. Pollen-derived bioactive lipid mediators showed cross-reactivity, as well as functional similarities, to leukotrienes. TraidlHoffman et al. [18] suggested that the rapid release of fatty acids from pollen during contact with the mucosa may act as allergen-independent pro-inflammatory factors contributing to initiation, manifestation or aggravation of allergic inflammation. If considerable amounts of fatty acids are contained in pollen fragments, they may also play a role in airways sensitization.

\section{NAD $(P) H$ Oxidases}

Granulocytes contribute to the inflammatory response through the production of reactive oxygen species (ROS) by nicotinamide adenine dinucleotide phosphate (reduced) (NAD $(\mathrm{P}) \mathrm{H})$ oxidase. Boldogh et al. [19] and Bacsi et al. [20] suggested that grass pollen contained sufficient endogenous $\mathrm{NAD}(\mathrm{P}) \mathrm{H}$ oxidase activity to trigger the recruitment of granulocytes, and the production of oxidative stress, even in the absence of the adaptive immune response. They also suggested that the ROS generated by pollen $\mathrm{NAD}(\mathrm{P}) \mathrm{H}$ oxidases provide a signal that enhances allergic airway inflammation. Recently, Bacsi et al. [14] showed that the cytoplasmic debris released from ruptured ragweed pollen grains is also rich in $\mathrm{NAD}(\mathrm{P}) \mathrm{H}$ oxidases. Thus, $\mathrm{NAD}(\mathrm{P}) \mathrm{H}$ oxidases are abundant in pollen fragments emitted from highly allergenic plants, although their occurrence in all living organisms is well known. With the use of a fluorescent particle sizer and a spectrometer, peaks in fluorescence have been detected in the outdoor air, and are believed to be from reduced pyridine nucleotides, such as $\mathrm{NAD}(\mathrm{P}) \mathrm{H}$, and flavonoids, that are contained within viable bacteria [21]. Whether the $\mathrm{NAD}(\mathrm{P}) \mathrm{H}$ or flavonoids housed within pollen or fungal fragments contributed to these observed peaks in fluorescence is not known.

Although ROS cause oxidative stress, such as molecular damage and aberrant signaling [22], they play diverse roles in plants, such as contributing to pollen tube growth [23]. It is likely that $\mathrm{NAD}(\mathrm{P}) \mathrm{H}$ oxidases are more abundant in hydrated and metabolically active pollen and pollen tubes, than in dormant mature pollen grains. The finding of $\mathrm{NAD}(\mathrm{P}) \mathrm{H}$ oxidases in pollen fragments, and their suspected role in asthma, suggests that inhibition of these pollen oxidases may provide a way to antagonize allergic inflammation. Proteases are also present in pollen, but are less effective at eliciting an airway response than NAD(P)H oxidases [14].

Pollen and Asthma

\section{Anti-Oxidants}

Concentrations of specific major bioaerosols have been correlated with allergy and asthma symptoms. A recent epidemiology-based study found that exposure of children to certain fungal spores, such as Penicillium, Aspergillus and Alternaria, was correlated with increased allergenicity, whereas co-exposure to other fungi, such as Cladosporium, was correlated with reduced allergic sensitization [24]. Although a protective role from certain types of exposure is consistent with the hygiene hypothesis, the chemistry underlying this is unknown. It has been speculated that some compounds may inhibit the response of the Th2 lymphocytes, but critical evidence is lacking [25].

If $\mathrm{NAD}(\mathrm{P}) \mathrm{H}$ oxidases and fatty acids contribute to asthma, then anti-oxidants and other substances that quench free radicals, that are contained in pollen fragments, or other inhaled bioaerosols, might play a role in suppressing the reactive oxidant response. However, there have been few clinical asthma reports involving airways challenges with anti-oxidants. Anti-oxidants in pollen are commonly proteins and phenolics, such as flavonoids. Although the most commonly occurring flavonoids in pollen are flavanol-3-o-diglycosides, each pollen species gives a unique fingerprint [26]. For example, orchard grass contains dactylin and isoquercitin, but timothy grass only contains dactylin. Some types of aglycones are specifically abundant in pine and Eucalyptus pollen. Pine pollen contains the flavonoid quercitin. The antioxidant properties and free radical-scavenging capability of these substances are mainly known from bee-collected pollen studies [27]. Anti-oxidant supplementary therapy has been claimed, in part, to be an effective approach in some asthma management cases [for review, see 28].

Reactive oxidant burst is a frequent plant cell response to attack by many microbes, such as plant-pathogenic ascomycete and basidiomycete fungi [29]. Some fungi secrete or release high levels of substances, such as mannitol, to suppress this reactive oxidant burst by the plants' defenses. Fungi can be rich in other protective anti-oxidants and free radical suppressors, such as carotenoid pigments in basidiomycetous rust fungus [30] and red yeast [31]. Respirable-sized particles are released into the atmosphere from a diversity of allergenic fungi $[32,33]$. Elbert et al. [34] reported on the occurrence of mannitolrich fluids that accompany rapidly discharged ascomycete and basidiomycete spores. Small intact yeast conidia are also inhalable, for example Aureobasidium, as are small intact spores of fungi, such as Aspergillus and Penicillium. The respirable-sized particles emitted from fungi

Int Arch Allergy Immunol 2007;144:162-170 

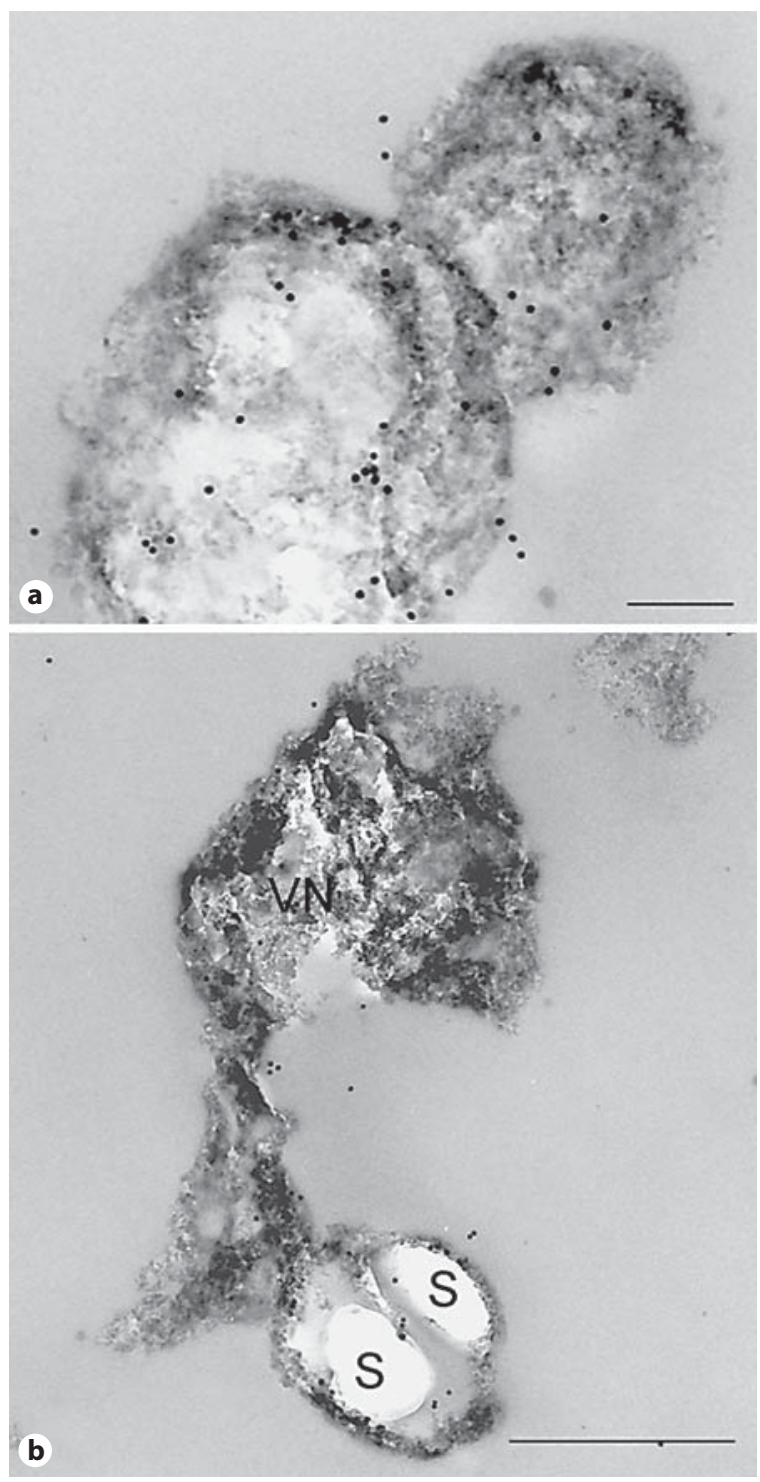

Fig. 3. Ryegrass pollen fragments sampled from the air of an emission chamber and embedded, sectioned and immuno-labeled for transmission electron microscopy [7]. a Pollen cytoplasmic debris showing localization of group 1 allergens. Scale bar $=0.2 \mu \mathrm{m}$. b Pollen fragment containing a vegetative nucleus (VN), 2 starch granules $(\mathrm{S})$ and attached cytoplasmic debris. Scale bar $=$ $1 \mu \mathrm{m}$.

and plants have quite different compositions not only with regards to proteins and carbohydrates, but to other substances, such as phenolics, that can also act as antioxidants and free radical suppressors. Whether exposure to ambient air containing these substances can directly suppress reactive oxidant stress, or otherwise ameliorate the immune response in the airways, is unknown.
How substances - such as oxidants and anti-oxidants, as well as proteins and proteases - are physically or chemically segregated to prevent interaction within the fragments of pollen cytoplasm is also not known. Pollen fragments, released into the air from flowers housed in a controlled emission chamber, have been sampled and embedded for transmission electron microscopy $[7,11]$. Despite the destructive rupture of the pollen grain, and the entrainment of the fragments into the air stream, the particles often possessed identifiable mitochondria, nuclei, sperm cells and p particles. These were often associated with starch granules, $0.5-2.5 \mu \mathrm{m}$ in diameter (fig. 3). Numerous particles of cytoplasm smaller than $0.5 \mu \mathrm{m}$ in diameter were generally not associated with starch granules. Thus, the compartmentalization of substances within the intact pollen grain is likely retained, at least in part, within the aerosolized pollen fragments.

\section{Anthropogenic Air Pollutants}

Another source of respirable particles in the atmosphere is from the combustion of fossil fuels. Interactions between these anthropogenic particles and particulate allergens are likely to occur from co-deposition in the airways, rather than coagulation in the atmosphere. However, atmospheric gases can interact with pollen and pollen fragments. Franze et al. [35] showed that pollen proteins, including the major birch allergens detected in environmental samples, are efficiently nitrated by polluted air. Immunological studies indicated a high allergenic potential for post-translationally modified proteins, and in particular for nitrated proteins [for review, see Doyle and Mamula, 36]. Thus, protein nitration by polluted air may promote allergies.

Behrendt and Becker [37] outlined the effect of pollutants on the bioavailability of pollen allergens, that is the rate of release of allergens from the pollen grain. Pollen grains absorbed heavy metals, $\mathrm{NO}_{2}$ and $\mathrm{SO}_{2}$. While $\mathrm{NO}_{2}$ showed no obvious effect, $\mathrm{SO}_{2}$ impaired leaching of group 5 allergens from grass pollen. Air pollution may also impact directly on the plant. Ozone pollution has been reported to depress grass pollen production [38], although increased atmospheric $\mathrm{CO}_{2}$ levels are known to stimulate plant growth and subsequent pollen yield.

Synergistic effects in the airways from the co-deposition of pollen particles and diesel pollutants containing carbon particles, polycyclic hydrocarbons, phenols and aza-heterocyclic compounds, lead to amplification of the immune system [39]. Although the pollutant composition is complex, advances have been made into understanding the immune response to specific components [40]. 


\section{Quantifying Atmospheric Pollen Allergens}

Numerous studies over the past 4 decades have reported the occurrence of pollen allergens in outdoor air samples of respirable-sized particles. Miguel et al. [41] present an overview of air sampling, detection and quantification techniques used in past studies of atmospheric pollen allergens. Several attempts have been made to quantify the concentrations of specific pollen allergens in the air, but sampling and analytical limitations have restricted the results to semi-quantitative data. Nevertheless, results showed peaks in respirable-sized pollen allergens after moist weather, often coincident with a nadir in pollen counts, and these have been correlated with increased hospital admissions and evaluations for asthma.

Chinese elm trees are one of the most allergenic plants in southern California, flowering in late August and early September. About 30\% of allergy patients are skin test positive to Chinese elm pollen. Recently, air samples were collected outdoors using liquid impingers (AGI-30 and AGI-4 all glass impingers). Chinese elm pollen antigens were detected using immuno-dot blots, and quantified by comparisons with a pollen extract standard curve [41]. Pollen counts and meteorological data were accumulated during the same period. Although the pollen grains are too large to penetrate the airways, pollen fragmentation has been observed for this species, and antigen concentrations of up to $266 \mathrm{ng} / \mathrm{m}^{3}$ of air were detected in the respirable-sized fraction.

In a recent study on olive pollen fragments, air was sampled with a multi-stage impactor onto fiberglass filters [42]. Extracts of the filters were bound to microtiter trays, and allergens were detected with enzyme-linked immunosorbent assay using horseradish peroxidase. $\mathrm{Pu}$ rified olive allergen was used for the standard curve. Olive pollen counts were recorded at up to $2,500 / \mathrm{m}^{3}$ of air, and the majority of the olive pollen antigen was detected in the filter which captured respirable particles.

Fully quantifying the threat that respirable allergens pose to asthmatic individuals requires future development of robust instrumentation that can accurately determine the allergen loading of the atmospheric aerosol. A halogen immunoassay has been developed to detect antigens associated with fungal particles greater than $1 \mu \mathrm{m}$ in diameter [33]. Fungal fragments were shown to express detectable allergen. Modifications to this technique to enable the respirable-sized fraction of air samples to be reliably analyzed would be useful.

To accurately sample and quantify respirable-sized allergens, a number of appropriate controls are required.
The sampler needs to be characterized to ascertain particle collection efficiency. Negative controls should be performed with filters collected well outside the pollen season, and an irrelevant antibody should be used in the immunoassay. Air samples may auto-fluoresce, or add background color to the filter. Background noise should be examined after the use of fluorochromes or color immuno-reagents, such as alkaline phosphatase. The signal should be compared to a standard curve prepared from a well-characterized pollen extract or recombinant allergen. Notably, the efficiency of filter extraction techniques needs to be assessed against spiked positive controls, that is the filter or air sample needs to be spiked with a known concentration to assess extraction recovery. Other than in the study by Miguel et al. [41], this crucial control has been absent from the published research. Loss of allergen during extraction and binding to the filter are serious problems that remain to be addressed.

\section{Thunderstorm Asthma Mechanism}

Thunderstorms have often been linked to epidemics of asthma, especially during the grass flowering season. Although biogenic aerosols are ubiquitous in the earth's atmosphere [43], current knowledge about the chemistry and physics of atmospheric bioaerosols is not very advanced [44]. Strong downdrafts and dry, cold outflows distinguish thunderstorm rain from frontal rain. We hypothesized that the weather system of a mature thunderstorm likely entrains grass pollen into the cloud base, where pollen rupture would be enhanced, and then transports the respirable-sized fragments of pollen debris to ground level where outflows distribute them ahead of the rain [45]. An additional factor that may influence pollen fragmentation under special circumstances are electric fields that might enhance allergen release and could be linked to the occurrence of 'thunderstorm asthma'. Direct observations are lacking, although demonstration of airborne release of respirable particles by pollen rupture would be a major new finding.

In laboratory experiments using glass microscope slides, ryegrass pollen undergoes considerable morphological changes when exposed to electric fields of magnitudes found in the outdoor air during a thunderstorm. Preliminary observations show the formation of a pollen tube, and some pollen rupture, even in dry air $(40 \% \mathrm{RH})$ [46]. The effect of electric fields was also observed, although less pronounced, on Bermuda grass pollen. But there was no apparent effect on Chinese elm pollen. The 
physiological reason behind this diversity of responses is currently being investigated. However, the results are consistent with the thunderstorm asthma hypothesis that suggests ryegrass pollen, in particular, is strongly implicated in this phenomenon [47].

\section{Airways Inflammation Related to Pollen}

The asthmatic response has been studied in asthmatics after provocation with allergen. Inhalation of ryegrass and other allergens as particles or purified proteins induces an immediate bronchospastic response as evidenced by a fall in airflow timed measurements within the first $60 \mathrm{~min}$ after challenge. This is referred to as the early asthmatic response and is associated with the release of histamine from basophiles and mast cells. After the early asthmatic response to inhaled allergens, the airflow normalizes and a secondary asthmatic response occurs 2-24 h later (late asthmatic response, LAR). The LAR is associated with the attraction of lymphocytes, eosinophils and basophils from the blood stream into the bronchial walls and airways. The bronchospasm and airways inflammation of the LAR is caused by the release of newly formed mediators from the recruited and resident inflammatory cells, such as leucotrienes, chemokines, cytokines and other pro-inflammatory mediators [48].

Grass pollen cytoplasmic fragments were introduced into the airways of grass pollen-sensitized rats and produced a greater inflammatory response than whole pollen or pollen extract [16]. The particulate nature of the pollen cytoplasmic fragments likely amplifies the immune response in the airways [49]. This may also be due to a more efficient binding of pollen fragments to antigen-presenting cells [50] and deeper penetration of pollen fragments into the airways [16]. The experimental data of Bacsi et al. [14, 20], Boldogh et al. [19] and TraidlHoffman et al. [15] provide additional evidence that pollen fragments, containing $\mathrm{NAD}(\mathrm{P}) \mathrm{H}$ oxidases and lipid particles, can amplify the immune response by producing ROS as well as chemo-attractants. Evidence of activated $\mathrm{T}$ cells and mast cells has been observed, using bronchoscopy and bronchial alveolar lavage, in atopic grass-sensitive asthmatics during the grass pollen season [51]. However, decreased lung function was not found in the small number of asthmatics studied.

Current prospective studies are being performed in Eugene, Oregon, the area of the highest grass pollen counts in the USA $\left(>1,500\right.$ pollen grains $/ \mathrm{m}^{3}$ of air). Asthma evaluations monitored at the Sacred Heart Hospital,
Eugene, from April to July 2006, showed an increase of up to 5 -fold exacerbations in June that correlated with the peak pollen counts in June. Asthma exacerbations were correlated with rainfall, as well as wind speed and direction, in May 2006, when the pollen counts were less than $50 / \mathrm{m}^{3}$ of air. Pollen fragments collected in the 5- and 2$\mu \mathrm{m}$ cut-off stages of a micro-orifice uniform deposit impactor are currently being analyzed for grass-allergenic protein.

Asthmatics are subjected on a daily basis to inhalation of aerosols of pollen, pollen fragments, air pollutants and other caustic chemicals. The relative importance of this mixture of pro-inflammatory agents in the airways and their interactions needs to be carefully dissected in order to understand the pathophysiology of the various stages of the asthmatic response. From our chamber studies of meteorologic responses of pollen fragmentation and aerosolization, it is likely that pollen fragments of respirable size are inhaled and may play an important role in asthma provocation in atopic, and perhaps even nonatopic, asthmatics.

\section{Conclusions}

Laboratory studies, used as a basis for interpretation of ambient data, have helped define a role for weather in pollen release and fragmentation. The importance of fragmentation, and an understanding of the means by which this occurs, may prove essential to understanding the risk factors for asthmatic patients that show allergic reactions to specific pollen allergens. Continued research is needed into how naturally occurring respirable-sized particles and air pollutants interact after co-deposition within the airways where they might enhance, or possibly ameliorate, asthma. Molecular or therapeutic approaches might then be developed for suppressing interactions at the pollen fragment/airway interface, or by inhibiting subsequent mediator release.

\section{Acknowledgments}

J.M.H. and M.M.G. were supported by the Southern California Environmental Health Sciences Center (NIEHS grant No. 5P30 ES07048), Philip Morris USA Inc., Philip Morris International, the Ayrshire Foundation and the Wallis Foundation. We thank Dr. Edward Newbigin, Melbourne University, for access to pollen count data. 


\section{References}

-1 Selgrade MK, Lemanske RF, Gilmour MI, Neas LM, Ward MDW, Henneberger PK, Weissman DN, Hoppin JA, Dietert RR, Sly PD, Geller AM, Enright PL, Backus GS, Bromberg PA, Germolec DR, Yeatts KB: Induction of asthma and the environment: what we know and need to know. Environ Health Perspect 2006;114:615-619.

$\checkmark 2$ Kemp AS, Mullins RJ, Weiner JM: The allergy epidemic: what is the Australian response? Med J Aust 2006;185:226-227.

$\checkmark 3$ Koppelman GH: Gene by environment interactions in asthma. Curr Allergy Asthma Rep 2006;6:103-111.

4 Zeldin DC, Eggleston P, Chapman M, Piedimonte G, Renz H, Peden D: How exposures to biologics influence the induction and incidence of asthma. Environ Health Perspect 2006;114:620-626.

5 Gilmour MI, Jaakkola MS, London SJ, Nel $\mathrm{AE}$, Rogers CA: How exposure to environmental tobacco smoke, outdoor air pollutants and increased pollen burdens influences the incidence of asthma. Environ Health Perspect 2006;114:627-633.

6 Wilson AF, Novey HS, Berke RA, Surprena EL: Deposition of inhaled pollen and pollen extracts in human airways. N Engl J Med 1973;288:1056-1058.

7 Taylor PE, Flagan R, Valenta R, Glovsky MM: Release of allergens in respirable aerosols: a link between grass pollen and asthma. J Allergy Clin Immunol 2002;109:51-56.

8 Glovsky MM, Taylor PE, Esch R, Miguel AG, House J, Tran L and Flagan RC: Respirable allergenic aerosols produced from pollen and molds; in Sepiashvili R: Asthma: From Genes to Clinical Management. Bologna, Monduzzi Editore, 2003, pp 155-160.

9 Grote M, Valenta R, Reichelt R: Abortive pollen germination: a mechanism of allergen release in birch, alder, and hazel revealed by immuno-gold electron microscopy. J Allergy Clin Immunol 2003;111:1017-1023.

>10 Taylor PE, Flagan R, Miguel AG, Valenta R, Glovsky MM: Birch pollen rupture and the release of aerosols of respirable allergens. Clin Exp Allergy 2004;34:1591-1596.

$\checkmark 11$ Taylor PE, Card G, House J, Dickinson MH, Flagan RC: High-speed pollen release in the white mulberry tree, Morus alba L. Sex Plant Reprod 2006;18:19-24.

-12 Vinckier S, Cadot P, Grote M, Ceuppens JL, Smets E: Orbicules do not significantly contribute to the allergenic micro-aerosol emitted from birch trees. Allergy 2006;61:12431244.

-13 Verdino P: Structural characterization of pollen allergens. Clin Rev Allergy Immunol 2006;30:73-95.

-14 Bacsi A, Choudhury BK, Dharajiya N, Sur S, Boldogh I: Subpollen particles: carriers of allergenic proteins and oxidases. J Allergy Clin Immunol 2006;118:844-850.
5 Traidl-Hoffman C, Kasche A, Jakob T, Huger M, Plotz S, Feussner I, Ring J, Behrendt $\mathrm{H}$ : Lipid mediators from pollen act as chemoattractants and activators of polymorphonuclear granulocytes. J Allergy Clin Immunol 2002;109:831-838.

16 Motta AC, Dormans JA, Peltre G, Lacroix G, Bois FY, Steerenberg PA: Intratracheal instillation of cytoplasmic granules from Phleum pratense pollen induces IgE- and cell-mediated responses in the Brown Norway rat. Int Arch Allergy Immunol 2004; 135:24-29.

17 Shin J-S, Shelburne CP, Jin C, LeFurgey EA, Abraham SN: Harboring of particulate allergens within secretory compartments by mast cells following IgE/FceRI-lipid raft-mediated phagocytosis. J Immunol 2006;177:57915800.

18 Traidl-Hoffman C, Kasche A, Menzel A, Jakob T, Thiel M, Ring J, Behrendt H: Impact of pollen on human health: more than allergen carriers? Int Arch Allergy Immunol 2003;131:1-13.

19 Boldogh I, Bacsi A, Choudhury BK, Dharajiya N, Alam R, Hazra TK, Mitra S, Goldblum RM, Sur S: ROS generated by a pollen NADPH oxidase provide a signal that augments antigen-induced allergic airway inflammation. J Clin Invest 2005;115:21692179.

20 Bacsi A, Dharajiya N, Choudhury BK, Boldogh I: Effect of pollen-mediated oxidative stress on immediate hypersensitivity reactions and late-phase inflammation in allergic conjunctivitis. J Allergy Clin Immunol $2005 ; 116: 836-843$.

21 Laflamme C, Verreault D, Ho J, Duchaine C: Flow cytometry sorting protocol of Bacillus spore using ultraviolet laser and autofluorescence as main sorting criterion. J Fluoresc 2006; 16:733-737.

22 Ritsick DR, Lambeth JD: Spring breezes, wheezes and pollen oxidases. J Clin Invest 2006;115:2067-2069.

23 Carol RJ, Dolan L: The role of reactive oxygen species in cell growth: lessons from root hairs. J Exp Bot 2006;57:1829-1834.

24 Osborne M, Reponen T, Adhikari A, Cho SH, Grinshpun SA, Levin L, Bernstein DI, LeMasters G: Specific fungal exposures, allergic sensitization, and rhinitis in infants. Pediat Allergy Immunol 2006;17:450-457.

25 Brown VG, Ennis M: T cell cytokine production in childhood asthma. Curr Resp Med Rev 2005;1:1-6.

26 Campos MG, Webby RF, Markham KR: The unique occurrence of the flavone aglycone tricetin in Myrtaceae pollen. Z Naturforsch 2002;57:944-946.
27 Campos MG, Webby RF, Markham KR, Mitchell KA, Da Cunha AP: Age-induced diminution of free radical scavenging capacity in bee pollens and the contribution of constituent flavonoids. J Agric Food Chem 2003;51:742-745

28 Riccioni G, D’Orazio N: The role of selenium, zinc and antioxidant vitamin supplementation in the treatment of bronchial asthma: adjuvant or not? Expert Opin Investig Drugs 2005;14:1145-1155.

29 O’Connell RJ, Panstruga R: Tête à tête inside a plant cell: plants and biotrophic fungi and oomycetes. New Phytol 2006;171:699-718.

30 Davoli P, Mierau V, Weber RWS: Carotenoids and fatty acids in red yeasts Sporobolomyces roseus and Rhodotorula glutinis. App Biochem Microbiol 2004;40:392-397.

-31 Davoli P, Weber RWS: Identification and quantification of carotenoid pigments in aeciospores of the daisy rust fungus, Puccinia distincta. Phytochemistry 2002;60:309-313.

32 Gorny RL: Filamentous microorganisms and their fragments in indoor air - a review. Ann Agric Environ Med 2004;11:185-197.

33 Green BJ, Tovey ER, Sercombe JK, Blachere FM, Beezhold DH, Schmechel D: Airborne fungal fragments and allergenicity. Med Mycol 2006;44:5245-5255.

34 Elbert W, Taylor PE, Andreae MO, Poschl U: Contribution of fungi to primary aerosols in the atmosphere: active discharge of spores, carbohydrates, and inorganic ions by Ascoand Basidiomycota. Atmos Chem Phys Disc 2006;6:11317-11355.

>35 Franze T, Weller MG, Niessner R, Poschl U: Protein nitration by polluted air. Environ Sci Technol 2005;39:1673-1678.

36 Doyle HA, Mamula MJ: Posttranslational protein modifications in antigen recognition and autoimmunity. Trends Immunol 2001; 22:443-449.

37 Behrendt H, Becker WM: Localization, release and bioavailability of pollen allergens: the influence of environmental factors. Curr Opin Immunol 2001;13:709-715.

38 Schoene K, Franz J-Th, Masuch G: The effect of ozone on pollen development in Lolium perenne L. Environ Pollut 2004;131:347354

39 Saxon A, Diaz-Sanchez D: Air pollution and allergy: you are what you breathe. Nat Immunol 2005;6:223.

40 Matschulat D, Prestel H, Haider F, Niessner R, Knopp D: Immunization with soot from a non-combustion process provokes formation of antibodies against polycyclic aromatic hydrocarbons. J Immunol Meth 2006;310: 159-170.

$>41$ Miguel AG, Taylor PE, House J, Glovsky MM, Flagan R: Meteorological influences on respirable fragment release from Chinese elm pollen. Aerosol Sci Technol 2006;40: 690-696. 
-42 De Linares C, Nietro-Lugilde D, Alba F, Diaz de la Guardia C, Galán C, Trigo MM: Detection of airborne allergen (Ole e 1) in relation to Olea europaea pollen in S Spain. Clin Exp Allergy 2007;37:125-132.

-43 Jaenicke R: Abundance of cellular material and proteins in the atmosphere. Science 2005;308:73-73.

44 Ariya PA, Amyot M: New directions: the role of bioaerosols in atmospheric chemistry and physics. Atmos Environ 2004;38:12311232.

45 Taylor PE, Jonsson H: Thunderstorm asthma. Curr Allergy Asthma Rep 2004;4:409413.
46 Vaidyanathan V, Miguel AG, Taylor PE, Flagan RC, Glovsky MM: Effects of electric fields on pollen rupture. J Allergy Clin Immunol 2006;117:S157.

47 Suphioglu C, Singh MB, Taylor P, Bellomo R, Holmes P, Puy R, Knox RB: Mechanism of grass pollen induced asthma. Lancet 1992; 399:569-572.

48 Metzger WJ, Zavala D, Richerson HB, Moseley P, Iwamota P, Monick M, Sjoerdsma K, Hunninghake GW: Local allergen challenge and bronchoalveolar lavage of allergic asthmatic lungs - description of the model and local airway inflammation. Am Rev Resp Dis 1987; 135:433-440.

49 Nygaard UC, Aase A, Lovik M: The allergy adjuvant effect of particles - genetic factors influence antibody and cytokine responses. BMC Immunol 2005;6:11.
50 Currie AJ, Steward GA, McWilliams AS: Alveolar macrophages bind and phagocytose allergen-containing pollen starch granules via C-type lectin and integrin receptors: implications for airway inflammatory disease. J Immunol 2000;164:3878-3886.

51 Djukanovic R, Lai CKW, Wilson JW, Britten KM, Wilson SJ, Roche WR, Howarth PH, Holgate ST: Bronchial mucosal manifestations of atopy - a comparison of markers of inflammation between atopic asthmatics, atopic nonasthmatics and healthy controls. Eur Respir J 1992;5:538-544. 